\title{
On the Necessity of Flying and of not Flying
}

\author{
Exploring how Computer Scientists Reason about Academic Travel
}

\author{
Elina Eriksson \\ KTH Royal Institute of Technology \\ Stockholm, Sweden \\ elina@kth.se \\ Markus Robèrt \\ KTH Royal Institute of Technology \\ Stockholm, Sweden \\ mrobert@kth.se
}

\author{
Daniel Pargman \\ KTH Royal Institute of Technology \\ Stockholm, Sweden \\ pargman@kth.se \\ Jarmo Laaksolahti \\ KTH Royal Institute of Technology \\ Stockholm, Sweden \\ jarmola@kth.se
}

\begin{abstract}
In order to fulfill the Paris agreement, we need to drastically reduce carbon emissions globally. 2020 is a pivotal year in this endeavour as many projections indicate that emissions need to decrease significantly before 2030. This challenge pertains to all parts of society, including (computer science) researchers. This however clashes with the fact that flying to a large extent has become built-in to the everyday practices of research and of academic life. It is feasible to imagine that computer scientists could fly less than other academics since we ought to be innovators and early adopters of computer-mediated alternatives such as video-conferencing and other forms of digital meeting technologies. It is however also possible that we fly more because conferences might be a more dominant outlet for publications in our field in comparison to other research fields. At KTH Royal Institute of Technology, the researchers at the School of Electrical Engineering and Computer Science (EECS) fly the most. In this paper, we present initial qualitative results from a survey regarding travel that was answered by computer scientists at EECS. We are in particular analysing the free text answers in order to understand how computer scientists ${ }^{1}$ reason about their own flying and about the alternatives. It will be hard to fulfil the Paris agreement without decreasing flying significantly, but this requires us to rethink how we do research, and how we travel (or not) within academia. This paper contributes with knowledge about the perceived barriers and drivers for computer scientists to decrease their flying.
\end{abstract}

\section{CCS CONCEPTS}

- Human-centered computing $\rightarrow$ Empirical studies in HCI; Empirical studies in collaborative and social computing; $\bullet$ Social and professional topics $\rightarrow$ Sustainability.

\footnotetext{
${ }^{1}$ We use computer scientists in this paper generously, referring here to any researcher who does research in ICT-related fields, including electrical engineering, software engineering, computer science and human-computer interaction.

Permission to make digital or hard copies of part or all of this work for personal or classroom use is granted without fee provided that copies are not made or distributed for profit or commercial advantage and that copies bear this notice and the full citation on the first page. Copyrights for third-party components of this work must be honored.

For all other uses, contact the owner/author(s).

ICT4S2020, June 21-26, 2020, Bristol, United Kingdom

(C) 2020 Copyright held by the owner/author(s)

ACM ISBN 978-1-4503-7595-5/20/06.

https://doi.org/10.1145/3401335.3401582
}

\section{KEYWORDS}

academic flying, computer science, carbon emission, sustainability

\section{ACM Reference Format:}

Elina Eriksson, Daniel Pargman, Markus Robèrt, and Jarmo Laaksolahti. 2020. On the Necessity of Flying and of not Flying: Exploring how Computer Scientists Reason about Academic Travel. In 7th International Conference on ICT for Sustainability (ICT4S2020), June 21-26, 2020, Bristol, United Kingdom. ACM, New York, NY, USA, 9 pages. https://doi.org/10.1145/3401335.3401582

\section{INTRODUCTION}

According to Rockström et al. [19], 2020 is an important year since it is the year when global $\mathrm{CO} 2$ emission curves need to change direction from their upwards march with new annual "records" of $\mathrm{CO} 2$ in the atmosphere to instead decrease every year from now. More specifically we need to decrease our carbon emissions by at least $50 \%$ every decade from now if we are to fulfill the Paris agreement. These proposed reductions, coined "the Carbon Law" by Rockström et al. [19], apply to all sectors and all levels of society - from the global, to the local as well as the individual level [3]. While 2018 IEA data suggests that direct emissions from aviation represents around $2.5 \%$ of global energy-related $\mathrm{CO} 2$ emissions $^{2}$, it does not include aviation-related emission sources (embodied energy costs of manufacturing airplanes, energy costs for operating airports, etc. see further Liu et al. 2016) or the so-called radiative forcing (RF) or high-altitude effect of aviation [13, 14]. Taken together, aviation could easily be attributed $5 \%$ or more of human climate impact and can easily account for a large or even major part of an individual's or a knowledge-intensive organisation's carbon emission ${ }^{3}$. This is particularly true for academia where, at least in some disciplines, an integrated and ingrained culture of flying has been established (to do fieldwork, to undertake longer or shorter exchanges, to disseminate results including giving talks and attending conferences, etc.) [11]. Flying can thus be the cause of a considerable part of the carbon footprint of a research-intensive university. At the same time, universities are a major source of knowledge about climate change, its consequences and how it can be mitigated. Yet, for the most part we do not seem to take the knowledge that we ourselves produce

\footnotetext{
${ }^{2}$ See further https://www.iea.org/reports/tracking-transport-2019/aviation\#abstract ${ }^{3}$ For one particular detail-oriented Belgian $\mathrm{PhD}$ student, it was calculated that $74 \%$ of the climate change impact of the whole $\mathrm{PhD}$ project could be attributed to mobility [1] and that mobility in this particular case for the most part was equivalent to air trave (which constituted $95 \%$ of this $\mathrm{PhD}$ student's mobility-related climate change impact).
} 
into account in our own practices [7]. It is thus possible to pose the question: if we cannot decrease our "excessive" carbon emission in academia, why then should others care, and, why then should others act on the information we produce? This concern has also been raised by an increasing number of students through different student-organized protests as well as by outspoken employees.

In this paper we will address academic flying in general and computer scientists' flying in particular. Working in a field that develops technologies that could alleviate the need of being present in person (e.g. teleconferencing and other collaborative digital tools), one might expect that computer scientists would fly less than other researchers. On the other hand, Computer scientists could fly more than other researchers because conferences are comparatively more important as a publication venue compared to journals in relation to researchers in other fields. The empirical data we are working with in this paper has been collected at the School of Electrical Engineering and Computer Science (EECS) at KTH Royal Institute of Technology in Sweden. In an ongoing process to understand and to decrease carbon emissions at KTH, a travel survey was sent out to all employees during the spring of 2019. In this paper, we will not analyse the flying in itself (but we can disclose that the EECS school flies the most at KTH), but rather how computer scientists reason about the necessity of flying (or of not flying). Only when we understand this reasoning can we formulate effective measures to address carbon emissions from academic flying.

\section{BACKGROUND}

If we are to reach the Paris agreement, we need to decrease carbon emissions by at least $50 \%$ every decade between now and 2050 [3]. That means every individual, every organisation, every nation and every branch of industry has to reduce their carbon emissions by $50 \%$ between $2020-2030$. While flying constitutes a relatively small part of total emissions, these emissions are produced by a global elite - a small minority of the global population.

Many aspects of flying have been studied; who flies, how has flying increased, why do we fly (business, tourism, visiting friends and family, etc.), how is flying incorporated into affluent and middleclass Western lifestyles, etc. [8, 9]. In this paper we are particularly interested in, and, engage with the subset of studies that have studied academic flying in particular. The study of academic flying is not a "research field" but rather an issue that has been studied by a loose network of researchers from a variety of disciplines, e.g. sociology, geography, (sustainable) tourism, mobility studies, etc. In addition of being an issue that can, and has been, investigated by some researchers, decreasing academic flying is also a practical challenge that engages an increasing number of universities (and then most often by university administrations). Hardly a month passes by without a new initiative or a new tougher policy being launched at some European university and there is now an increased interest in these questions both in Sweden, in other European countries and elsewhere (such as in particular and for obvious reasons in Oceania, see further $[6,7,7,10-12]$. This is evidenced for example by blogs ${ }^{4}$, discussion fora (such as the Roundtable of Sustainable

${ }^{4}$ See for example No Fly Climate Sci (https://noflyclimatesci.org) and Flying Less Reducing Academia's Carbon Footprint (https://academicflyingblog.wordpress.com).
Academic Flying) ${ }^{5}$, and the recent (November 2019) symposium on "Reducing flying in academia" that was held at the University of Sheffield (UK) ${ }^{6}$ and where it was possible to attend the symposium either in person or to participate remotely.

Based on our own knowledge of how research is conducted in Sweden in general, and at KTH in particular, we know that breaking "the flying habit" might be harder at a research-intensive university than in just about any other organisation. A researcher who has successfully applied for, and, received a research grant, has farreaching authority to decide exactly how that money is to be spent, e.g. to decide how and when to present research results at various conference venues around the world. The costs of travelling are usually insignificant compared to costs for salaries and it is hard for a head of a department or a school, or even for the university chancellor to "forbid" travel, not the least since it can be argued that dissemination of research results is not an incidental but rather a central part of any research project.

KTH Royal Institute of Technology, is a research-intensive technical university that is situated in Stockholm, Sweden. KTH has pledged to become a leading technical university in sustainable development and to contribute to the UN sustainable development goals (SDGs). This includes being a leader in mitigating climate change and to work actively towards a transition to a more sustainable society. KTH's efforts span education, research and engagement with external actors and KTH has developed climate objectives and measures for 2020-2045 that are in line with global climate targets.

As a background, an initial baseline of travel emissions at KTH was set in 2016, showing that the average emissions per full-time employee were $4800 \mathrm{~kg} \mathrm{CO} 2 /$ year, which is about half of the total emissions of the average Swede per year. KTH's costs for flying and other travel amounted to 44 MSEK during 2016. It was however evident that aviation and in particular long-distance (intercontinental) travel was by far the most significant source of travel-related emissions at KTH, with flying being the source of $99 \%$ of the total emissions from business travel (which includes rail, boat and car transport). Consequently, an action plan and a regular follow-uproutine of employee travel was launched in 2018, based on the modelling framework and process tool CERO $[17,18]$.

At the first follow-up in 2019, flight emissions (as registered by KTHs travel agency) had increased by $28 \%$ per capita since 2016. However, part of that increase can be explained by the fact that employee compliance with travel routines had increased between 2016 and 2019, as employees had become better at booking trips through KTH's contracted travel agency. In 2016 a larger proportion of the trips were "self-booked" journeys that were not tracked and thus did not register in the baseline numbers.

Based on the follow-up results from 2019, an updated target scenario and action plan has been developed and anchored at the KTH chancellor level, "KTH's Climate objectives and measures for 2020-2045". As of January 2020, the climate framework at KTH includes an emission reduction plan which stipulates that $\mathrm{KTH}$ must decrease its $\mathrm{CO} 2$ emissions by at least $60 \%$ (in terms of carbon dioxide equivalents per annual workforce) during the present

\footnotetext{
${ }^{5}$ See further https://businesstravelroundtable.ac/about.

${ }^{6}$ See further https://www.sheffield.ac.uk/reducing-academic-flying-symposium.
} 
decade (2020-2030) and with a sub-target of attaining 40\% CO2reductions by 2025 . These are bold but necessary goals that have been formulated against the backdrop of KTH's lack of success to attain earlier CO2 reduction goals for the 2016-2020 period. It is clear that something - perhaps radical - must happen if KTH is to change the direction of its hitherto increasing $\mathrm{CO} 2$ emissions from travelling. Data from the 2016-2020 period has this far been broken down and presented at a high level, e.g. per school, but any deeper understanding of travel patterns have this far been lacking (who flies when, where and why?). In order to fully understand the possibilities and conditions for changing employee travel behaviors, there is an urgent need for better data and a better understanding of travel and meeting-related practices at a school, department, division, and even at the individual level, something that the authors of this paper are working on in a newly started research project, "Decreased CO2-emissions in flight-intensive organisations: from data to practice".

In this paper we will focus on the School of Electrical Engineering and Computer Science (EECS) at KTH. EECS conducts research and education within the areas of electrical engineering, computer science, and information and communication technology. There are around 200 faculty members, 360 doctoral students and 230 members of research and teaching staff at the school as well as around 4400 students annually in various bachelor's and master's programmes at the school. At KTH Royal Institute of Technology, employees at the School of Electrical Engineering and Computer Science (EECS) fly the most in terms of carbon emissions. In 2019 , total direct flight-related emissions by EECS employees amounted to 1816 tons. Emissions at the other four schools at KTH range from 976 to 1421 tons per school. We will not analyse this fact further in this paper, but we do present results from the 2019 CERO travel survey that was answered by computer scientists at EECS and these answers could be seen as a background to finding the drivers and barriers to reduced flying for academics. We have in particular analysed the free text answers as to understand how KTH computer scientists reason about their own flying and about the alternatives to flying.

\section{METHOD}

In order to start exploring computer scientists' reasoning around their own flying, we have in this paper analyzed the free text answers that were submitted in the CERO travel survey. The CERO survey is used in about 100 organizations following the CERO process, (see further Background). The overarching goal of using the CERO travel survey at KTH was to study the attitudes and travel preferences of business- and commute travel of KTH employees, since this data is hard to obtain from other sources. The KTH 2019 CERO survey included a few additional open-ended free text questions regarding business travel. The survey was sent out to all 3563 employees at KTH Royal Institute of Technology in June 2019, e.g. all faculty, postdocs, $\mathrm{PhD}$-students, administrative and technical staff as well as research engineers. The survey covered both commuting and business travel as well as alternatives to travelling such as non-travel and video conference meetings. Most of the questions were multiple choice questions, but also had the option of submitting additional comments as well as a few free text questions. The specific questions we focus on in this paper are;

- A large part of the emissions at KTH come from air travel. What do you think should be done to reduce these emissions?

- How do you contribute to KTH"s sustainability goals regarding reduced air travel?

- Do you experience any disadvantages with meetings via video conference or web meeting?

- Answers to the very last open ended question "Other comments?"

In this paper we focus on the answers from (only) the School of Electrical Engineering and Computer Science since we are particularly interested in the flying habits of researchers in the field of computing as well as of their reasoning in relation to their own flying. The response rate from the School of Electrical Engineering and Computer Science was $32 \%$ and the survey was anonymous. This means that the different answers cannot be tied to different job positions (such as $\mathrm{PhD}$-students or professors), nor is it possible to (for example) break down the answers by department, by gender or by age. In order to understand the material, the first author performed a thematic analysis of the free text answers in the qualitative analysis tool NVivo. The material was read through, coded according to initial emerging themes before the material was re-read and re-coded. The themes were discussed with the other authors, and the results of the analysis are summarized and presented below according to the final themes. Free text answers were given in either Swedish or English. Some of the quotes in English have been minimally altered for the sake of clarity (i.e. correcting spelling mistakes or adding missing words or punctuation marks). The Swedish quotes have been translated to English, the translations were read by all authors, and we have marked quotes that were originally in Swedish in the text below.

\section{RESULTS AND ANALYSIS}

The free text answers were analysed through a thematic analysis, and the results will be presented under four overarching themes: 1) is academic flying a legitimate concern? 2) flying as an inherent part of research, 3) the type of change needed, and 4) alternatives to flying.

\subsection{Is academic flying a legitimate concern?}

The survey generated a surprisingly large number of free text answers. This might have something to do with the public debate on climate change issues in general and the debate on flying in particular, for example in relation to the ongoing global school strikes by schoolchildren and youths. However, there has not been any widespread discussions about carbon emissions and flying at our university despite the fact that it has been pointed out as an important issue by the chancellor and vice chancellor for sustainability in a series of news articles and blog posts ${ }^{7}$. At the School of Electrical Engineering and Computer Science in particular, the topic has been even less prevalent, a non-issue, and in some parts

${ }^{7}$ See for example: https://www.kth.se/blogs/hallbart/2017/03/flygresor-storstautslappskallan-for-kth/ 
perhaps even off limits as an issue that is up for discussion, as this respondent suggests:

I don't know if this is the right place to say this, but there is kind of a culture of silence concerning climate issues and travel at KTH. Everyone knows about it, but it is considered unfitting to talk about it, even our head of division has directly said that we should not discuss the climate impact of our travel. (original in Swedish.)

Whether this culture of silence is a conscious strategy or if it is part of what can be described as a social construction of denial [16] is hard to tell. Furthermore, the frequency with which travelling is raised as a legitimate topic for discussions will certainly differ between different departments and divisions. It is also clear from the results that the engagement in the issue spans a large continuum where there is, on the one hand, an outright dismissal of academic flying as a contributor to global carbon emissions, and, on the other hand respondents who stated that they voluntarily had stopped flying altogether. Examples of the former are:

KTH should increase its flying; an excellent way of making great contacts. Sustainability goals are a political hoax (original in Swedish.)

Are you really kidding me by giving me the impression that $K T H$ researchers and academics in general are the primary force behind air travel emissions. Next time when you take a flight ask how many academics there are in the flight. You will get your answers.

The idea that carbon emissions from any one person, organisation or even country are very low in comparison to the larger whole and that any reductions would be meaningless is a recurring argument among climate deniers as well as others. However, the climate change issue is now so pressing that this argument is moot as all sectors in society as well as all countries, organisations, and individuals, need to decrease emissions substantially and repeatedly [3]. In examples from the other end of the spectrum some computing researchers are so concerned about climate change that they state that they have stopped flying altogether. This is exemplified by the following quotes:

Since fanuary 1, 2019, I have stopped flying for work, so it will be train, boat or video conferencing instead. (original in Swedish.)

I can also mention that I don't fly at all nowadays, which means that I only travel for work if it is possible to do so without flying. (original in Swedish.)

This might be particular to a Swedish context where during 2019 there was much media attention on the adverse effects from flying, where the concept of "flygskam" (flight shame) was coined, and where the social movement "Vi stannar på jorden"8 was started [23]. Although this discourse is present in Sweden, there is less evidence that this is the case in other countries. Furthermore, there are few examples of computer scientists who have publicly pledged to stop flying, even though the issue of flying has been problematized for

\footnotetext{
8"Vi stannar på jorden" means "We stay on the ground", and the campaign launched by the movement asked people if they would not fly during 2019 if 100000 other people pledged the same thing on social media, a similar campaign would be launched for 2020 .
}

quite some time within the field of Human-Computer Interaction by for example Strengers [22].

It should be noted that a majority of the responses lay somewhere in-between these extremes, but it is clear that a majority of the respondents who had written free text answers knew that carbon emissions from flying was a legitimate concern but who simultaneously did not see any easy solution to that issue with regards to their own business travel.

\subsection{Flying as an inherent part of research}

Despite a few answers that directly dismissed the environmental impact of academic flying, most acknowledge that something needs to be done, but that it is a complex issue, as exemplified in this rather long reflection:

Human contacts/presentations are very important in
Academia. I understand that we must reduce our emis-
sions, but if we reduce the number of trips of our re-
searchers, the impact of our research will significantly
decrease. Trips are used to disseminate our research. This
will increase the impact of our research. Trips are also
used to create contacts, and these contacts will be used
for common applications in Europe. Finally, trips are
used to enable contacts with industrial partners abroad
and other funders. The only way that I see to reduce
emissions is in short trips, in which we could encourage
the use of trains instead of planes. Maybe, to recom-
mend to the professors to attend conferences more in
Europe than in America/Asia/Oceania. Apart from that,
it is difficult.

What is pointed out here is that there are many different aspects of academic work that is dependent on travel such as dissemination of results (which in a computing field is heavily dependent on conferences), the "need" to establish international networks and to establish or maintain contacts with industrial partners [11, 20,21]. Even if it was not stated up front in the responses, one interpretation could be that if you want to be an excellent and successful researcher, you need to fly (i.e., mechanism that were pointed out by [11]). Sometimes, the respondents point to pressure from others, e.g. that there is an expectation that you need to travel:

I am expected to fly a lot in my line of work. Earlier I could attend 2 international conferences and similar per month. (original in Swedish.)

Exactly who has these expectations is not stated in the responses. But, even if such pressure exists, it is possible to see that many would like to see some kind of change, as is clear in the following quotes:

As a PhD-student (and a researcher in general), we must go to conferences abroad to publish. I think that KTH should push for it being possible to publish at conferences without being there in person. Perhaps through digital presentations or video recordings instead. (original in Swedish.)

Travelling to conferences is a must especially for Computer Science Students, because research in this area is fast paced. I wonder if KTH can do anything about 


\section{it, but if KTH strengthens its positions and pressurizes ACM and IEEE perhaps something could be done.}

One way to interpret these quotes is to stipulate that there are researchers at the School for Electrical Engineering and Computer Science who would like to fly less - if there were alternatives or if the perceived need was smaller. As of today, there seems to exist a goal conflict between on the one hand the goals of publishing internationally at conferences and on the other hand to reduce carbon emissions from flying. It is also clear from the responses that the respondents feel that they are part of a larger academic system that comprises colleagues and managers at KTH, as well as academia in general, and that this system exerts pressure, in the here and now, and that the system (including incentives and rewards) needs to change substantially if we are to see different behaviors at the level of the individual.

\subsection{Change harbors magnitudes}

In the responses, it was clear that the respondents presented ideas of how to counter carbon emissions from flying that could be attributed to different kinds of change, or, different magnitudes of change. Proposed measures can be mapped in terms of different magnitudes of change through 1) fine tuning of current practices, 2) introducing hard rules, 3) arguing that change must first happen beyond the university, or 4) changing the overarching system (e.g. society) altogether.

4.3.1 Fine tuning. A majority of responses were coded under "fine tuning" of different aspects of current practices. Many of these concerned different ways of encouraging researchers to take the train instead of flying, for example through presenting train relevant information when booking a trip, redesigning the booking system so that the option of taking the train becomes more prominent, or updating the travel policy to promote longer train trips in Europe. In the responses it was also clear that there were some misconceptions regarding the possibilities of taking the train since some argued that buying train tickets to the continent was not possible through the KTH's procured travel agency (which is possible if you contact them by phone or email). Other suggestions pointed to the fine tuning of flights per se, for example by choosing to fly newer and more fuel-efficient planes:

1. Choose daytime flights. Studies show that jet contrails (those white lines of exhaust that streak the sky behind planes) can contribute to warming the atmosphere because as they disperse, they can trap heat radiating up from the earth. This is especially true at night because during the day, the contrails partially offset the heat trap effect by radiating light from the sun away from the earth. 2. Pack light. Every pound of weight that a plane carries increases the amount of fuel that it burns, so reducing your luggage weight actually reduces your environmental impact - and it makes your luggage easier to carry, too! 3. Find an airline that uses newer model planes. Newer planes tend to offer better fuel economy than older ones.

This quote also exemplifies the fact that many respondents probably do not have a correct idea of how large the carbon emissions from flying are, and that more fuel-efficient planes will affect the relative emission reductions only marginally. Carbon offsets were also suggested as a way to reduce carbon emissions from flying, either through direct offsetting (like for example planting trees) or to make an offset internally at KTH that would be used to reduce the cost of booking train tickets.

Another fine-tuning proposal is the suggestion to not fly in opponents and grading committee at a dissertation but instead make them participate through video link. While the carbon emissions from such flights add up, this was still coded as fine tuning since it would not affect or make any demands on the travel practices of KTH researchers.

4.3.2 Hard rules. Another set of answers pointed at harsh, nonnegotiable limits by arguing for hard rules regarding flying, or by proposing quotas such as in the following quotes:

\begin{abstract}
KTH's chancellor should cap, by force, for every single Division of KTH, any travel exceeding $75 \%$ or even $50 \%$ of the previous year's $\mathrm{CO} 2$ emission of that Division. No travel requests okayed and no travel reimbursement beyond this limit. This would ENSURE reaching the goal. Nothing else will help significantly. This should be implemented as of Jan 2020.

It can be achieved in many ways. One way is a draconian decision that every employee has the right to a maximum of $x$ flight trips per year. Another is for every division to decrease their travelling with $x \%$ every year. When it comes to costs, people should always consider the emissions and choose the mode of transport with least emission. [...] I could imagine additional policy instruments, for example transparency so that we would know which divisions/persons that contribute the most to climate change. (original in Swedish.)
\end{abstract}

The last quote does not only point to hard rules, but also to introducing social pressure that would come as an effect of the increased transparency of presenting and comparing every division's carbon emissions from flying. At present this is not possible since carbon emission data is presented only at a school level and has not been broken down further to single departments or division, or even further to individual employees.

These hard rules are difficult to enforce in an academic setting, which is also pointed out in the responses, since researchers (at least in Sweden) have a large degree of autonomy as to how to use funding from research projects. Still, many respondents think that the management at KTH, including the chancellor, have the mandate to enforce these kinds of measures in order to reduce the carbon emissions from flying at KTH.

4.3.3 Beyond KTH. Some of the respondents pointed to solutions beyond KTH in the responses, such as policies, regulations and innovations that need to happen on national or even a global level in order to address carbon emissions from academic flying. An example of this is presented in the following quote:

Pushing authorities to put higher standards (energy consumption of engines, use of biofuels) and obligations on air companies. We researchers have to travel. We need 
to have the possibility to choose an environmentally friendly air company.

In this group of answers, there is a wide variety of things that "need to happen", for example developing better electrical cars, autonomous cars that could remove the demand for short haul flights, increased pressure on travel agencies and politicians to make train trips easier to book, better fuel efficiency, better biofuels, inventing new fuels, and "[i]nvent small nuclear reactors that cannot melt down and develop the thorium-mixed fuel which doesn't leave radioactive waste". What is also clear from the answers, is that many of these respondents either dismisses the problem of carbon emissions from academic flying, or believe that this is not a problem researchers at KTH can address, such as in the following quote:

Increase taxes on any carbon-dioxide emission worldwide to govern the problem through the price of the market offering. What definitively should not be done on a KTH level is to introduce yet another administrative layer (Write a paragraph for every flight travel that you are booking to justify why this travel is necessary). This is not a problem KTH can address efficiently.

As can be seen in both quotes in this section, the absolute necessity of academic flying is a strongly ingrained belief, and this makes it hard to see decreased flying as a viable, realistic option. Other answers however point to alternatives to flying, although some of the ideas go (far) beyond what is possible in the current system.

4.3.4 Changing the overarching system altogether. Several of the answers point to a larger system change either of the academic system or even the overarching political and economic system as in this quote:

There is only one way to handle the environmental catastrophe: abolish capitalism. KTH should do everything in its power (and some more) to accelerate this. (original in Swedish.)

While this answer represents an extreme view and points to the economic system beyond academia, most answers proposes changing how academic conference publications are valued, or how we do research such as in the following quote:

Influence the research society to lessen the chase for conference publications (and also the requirements for examination connected to this). Also the research society needs to be sustainable in the long run and change now that we have learnt about the human impact on the climate. (original in Swedish.)

In one sense, this is also beyond the possibilities of what KTH alone can do, but where researchers and managers at KTH are still part of the solution. Calls for changing the focus on conference publications and shifting to journal publications, or to make sure that grading committees or opponents should be able to attend remotely were also proposed as "things that need to happen" without specifying exactly who is responsible for this change or how it should come about.

\subsection{Alternatives to flying}

As for alternatives for flying, both train and videoconferencing were mentioned in many of the responses. Many of the respondents seemed to think that taking the train within Europe would be a viable option instead of flying:

That being said, for shorter trips, for example inside Europe, the use of trains is possible and in some cases preferable to taking an airplane. I would say the time is the issue here, providing some incentive for taking the train (for example excluding the travel time of the train from your travel report, giving bonus for using the train, etc.) could be a motivation for people to select that transportation. Completely removing the travel need from the equation is a different matter and again not always possible.

The quote points out that there is an additional issue that is important when taking the train, namely that it takes longer to travel to the destination. Another alternative that was explored in the responses were videoconferencing and remote participation, which was in principle viewed as a viable option, except for a current lack of suitable technologies. Despite KTH already having a centrally procured video conference system and dedicated videoconferencing seminar rooms, not all respondents knew this, or they felt that the system is inadequate.

Also, make it possible to have digital meetings in KTH conference rooms that don't require calling IT support or other help every time someone wants to use it. Also, it would help if we knew that the digital links were secure, for example not having the session keys owned by Microsoft or Google. The reason for this is that sometimes proprietary or other valuable information is discussed, and the consequences of giving such data away may be a reason to travel to a face to face meeting instead.

There are also responses that point to the things that are hard to do with the current systems, such as in the following quote:

[Videoconference] works well for simpler meetings, but it is difficult to use for meetings with many participants or when you need to write or draw something during the discussion. (original in Swedish.)

Overall, using videoconferencing is often suggested as an alternative to flying by the respondents. However, when looking at the quantitative answers, only $9 \%$ of the respondents state that their latest business travel could in fact have been replaced by a videoconference meeting.

\section{DISCUSSION}

In this paper we have presented an analysis of the free text answers from a travel survey answered by computer scientists at the school of Electrical Engineering and Computer Science at KTH Royal Institute of Technology. What becomes apparent in the answers is that many of the respondents knew there is a need to reduce carbon emissions, but that it is not clear to them exactly how such reductions should come about. Respondents explicitly mention that they experience pressure or a "need" to travel either in order to do research or to disseminate research results, and that this 
pressure is built into academic practices. This is in line with earlier research $[11,20,21]$. It is hard to know exactly where they perceive that such pressure comes from, since the respondents allude to unknown others or to academia in general in their answers. They are at the same time also aware of the necessity to not fly, or to fly considerably less, in order to reduce their own and KTH's carbon emissions [3].

The computer scientists in this corpus present a wide spectrum of reasoning all the way from outspoken dismissal of considering academic flying to be a problem, to those who have changed their practices and no longer fly at all. This wide spectrum of opinions is also a testimony to a lack of consensus that, in combination with researchers having a high degree of autonomy, would seem to make it hard to propose clear action plans that are acceptable by all and that could drive an agenda for change. This could mean that any action plan needs to be backed up with information regarding emissions, especially information that places carbon emissions from air travel in relation to other emissions, or information that clarifies the emissions from different types of flights such as (in a Swedish context) the huge difference between Nordic, European or intercontinental flights, see for example the flight emissions map ${ }^{9}$ This kind of relational knowledge of emissions is something that Wolrath-Söderberg and Wormbs [23] pointed to as being instrumental at triggering change in those individuals that had chosen to stop flying.

The corpus also presents a wide variety of suggestions of how to decrease carbon emissions from academic flying, ranging from fine tuning of current practices, to more far-reaching target-oriented changes to rules and regulations, or even to suggesting overarching change of "the system" (academic or otherwise). Some of the suggestions are clearly inadequate or will only lead to marginal decreases of carbon emissions (for example the suggestions to switch to more fuel-efficient airplanes or of packing light for the trip). It has to be stated that it will not be possible to fulfill the Paris agreement as modelled by the Carbon Law [19] (50\% carbon emission reductions for several decades in a row) or the KTH climate framework goals (60\% carbon emission reductions between 2020-2030) unless we fly less - and not just a bit less but rather considerably less. This idea seems to be difficult for many of the respondents to grasp (not to mention to accept or embrace it) - especially when it comes to their own practices of flying. It would be interesting to examine this phenomenon more closely, for example by conducting interviews that do not let respondents shy away from, or gloss over this uncomfortable contradiction - which might be an example of a classic case of cognitive dissonance $[4,5]$.

As compared to recent research on flying, this particular material did not mention any claims or references to morality or ethical considerations in relation to flying [8, 23]. In the study by WolrathSöderberg and Wormbs [23], the respondents stated that they have not been shamed into reconsidering flying, but rather that they personally have come to the conclusion that reducing flying is a moral issue. The reasons for why such considerations did not come up in our study could be explained by the formulation of the questions or the setting of the survey (work/professional setting at a technical university). The statement that comes closest to touching

\footnotetext{
${ }^{9}$ https://www.flightemissionmap.org/
}

upon such issues is perhaps that of a respondent who stated that discussing our own flying as academics is a topic that is shrouded in a culture of silence, which could be interpreted that carbon emissions from our travels are a problematic topic that should be avoided "in civilised company". To some degree this suggests that there might be a "social construction of denial" [16] concerning our academic practices' and their contribution to climate change. Having role models, or perceiving oneself to be a role model, seems to be an important driver for the respondents in Wolrath-Söderberg and Wormb's study [23]. This would imply, that a culture of silence around academic flying, and in particular around those who have already voluntarily reduced their flying, needs to be broken. We need to promote those good examples that exist, of individuals or places, that break new ground by exploring new academic practices that are less carbon intensive.

\subsection{Method discussion}

It should be pointed out that a weakness of the current study is that the dataset we have examined is by no means complete. First and foremost only $32 \%$ of the employees at the School of Electrical Engineering and Computer Science completed the survey, and not everyone chose to write free text answers (which is the material we have examined in this study). It is difficult to know how generalizable the results are even within the KTH School of Electrical Engineering and Computer Science since the survey was answered anonymously, and we thus do not have any data regarding for example demographics. It could presumably be the case that those with strong opinions on the matter are overrepresented in the survey, giving it the impression that the subject matter is more polarized than it might in fact be. It is however still important to map these diverse points of view since they will all be part of a narrative within which higher education organizations' actions to cut our carbon emissions from air travel are planned and executed (or not). Furthermore, in terms of KTH being a technical university and the school of Electrical Engineering and Computer Science being a large school that covers most computer science and computing disciplines, these results could be applicable also to other university settings. This is an exploratory study and future research will need to combine this (or similar) qualitative material with quantitative data in order to better discern patterns and correlations. This material for example does not really say anything about how much computer scientists fly, or for what purposes. These are issues that also need to be researched if we are to design effective interventions to reduce academic flying.

\subsection{Future research}

Regarding the issue of whether computer scientists fly more or fly less than researchers in other academic fields, better indicators need to be developed $[2,25]$. There is not only a need to better understand the tensions between travelling extensively and staying put [11,21], how flying is correlated with academic excellence [24, 25], but possibly also what potential (positive) impact our research has and weigh that against the carbon emissions we produce as we conduct and later disseminate research results. This would to some degree be in line with the reasoning by Mann et al. [15] who argue that we should examine and shift the maturity of ICT4S research. Such 
a shift would then need to happen not just within ICT4S nor just in computing but in research in general.

Another direction of future research would be to go into depth with developing more comprehensive and detailed understandings of individuals' and departments' flying patterns. This is something we will do during 2020 in our recently-started research project "Decreased CO2-emissions in flight-intensive organisations" where we will more specifically develop a workshop material that will be tested at five KTH divisions (one at each of the five Schools) in order to analyse reasons, practices, preferences and individual attitudes behind flying at division level, during the coming three years. As researchers in that project, we strongly believe that it is no longer a question of whether we need to reduce flying, but rather when, where and how "unnecessary flying" (however that is defined) should be reduced.

\section{CONCLUSION}

Since this is an exploratory qualitative study of computer scientists' reasoning about academic flying and carbon emissions from air travel, only limited conclusions can be drawn from it. However, within the framework of our study, there does seem to exist a group of academics, in this case computer scientists at $\mathrm{KTH}$, who do perceive academic flying as a problem. Some of these researchers have already taken measures to cut their carbon emission from flying. This is however a contested issue and any concerted effort to cut carbon emission from a top-down perspective needs to be accompanied by data and information that can help unify researchers as to what are the most efficient measures. The results from this study show that there are misconceptions or misunderstandings around what measures are efficient and about how large carbon emissions are from flying. This study also points to the necessity of change happening at several levels at the same time; some measures can be taken at university level, but the whole academic system also needs to grapple with what changes are necessary if we want to decrease carbon emissions at a pace that is in line with fulfilling the Paris agreement. Even researchers who have, or who want to reduce their carbon emissions seem to perceive a pressure from "the system" to publish at conferences, to conduct research visits and build international networks and hence to fly extensively. There is also a need to bring forward good examples that others can learn from and to break the perceived silence around the adverse effects of academic flying.

\section{POSTSCRIPT}

This paper was written before the Covid-19 virus was deemed to be a pandemic by the World Health Organization (WHO) and the camera-ready version was prepared at a time when many countries had taken severe actions to slow the spread of the virus. The authors want to point out that in light of the Covid-19 pandemic and related situation within higher education and academia (with an almost total ban on travel both within and between countries), many answers to a survey such as the ones reported upon here will surely change substantially in the coming years. Much that was previously regarded as preposterous has in a short amount of time been tried out on a massive scale, e.g. travel has been banned and most teaching as well as all conferences have been moved to online environments. Some of the things we point to as "future research" has in a short amount of time been tried out, albeit not voluntarily but as a response to an overwhelming and non-negotiable outside force. What then becomes important to do after the Covid-19 pandemic, is to embrace those academic practices that worked during this time and that also led to reduced emissions, without compromising quality either in research or education.

\section{ACKNOWLEDGMENTS}

We want to thank the anonymous reviewers for constructive feedback that made this paper better. Furthermore, we want to thank CERO for allowing us access to the qualitative data from the CERO travel survey. The research presented here has been performed with funding from The Swedish Energy Agency in the project "Decreased $\mathrm{CO} 2$-emissions in flight-intensive organisations: from data to practice" (48156-1).

\section{REFERENCES}

[1] Wouter MJ Achten, Joana Almeida, and Bart Muys. 2013. Carbon footprint of science: More than flying. Ecological indicators 34 (2013), 352-355.

[2] Joachim Ciers, Aleksandra Mandic, Laszlo Daniel Toth, and Giel Op't Veld. 2019. Carbon Footprint of Academic Air Travel: A Case Study in Switzerland. Sustainability 11, 1 (2019), 80.

[3] Johan Falk, Owen Gaffney, Avit K Bhowmik, Pernilla Bergmark, Victor Galaz, Nick Gaskell, Stefan Henningsson, Mattias Höjer, Lisa Jacobson, Krisztina Jónás, Tomas Kåberger, Daniel Klingenfeld, Jennifer Lenhart, Brent Loken, Dag Lundén, Jens Malmodin, Tove Malmqvist, Victoria Olausson, Ilona Otto, Anthony Pearce, Erik Pihl, and Tomer Shalit. 2019. Exponential Roadmap 1.5. Future earth, SITRA (2019)

[4] Leon Festinger. 1962. Cognitive dissonance. Scientific American 207, 4 (1962), 93-106.

[5] Leon Festinger, Henry Riecken, and Stanley Schachter. 1956. When prophecy fails. Minneapolis, MN, US.

[6] Andrew Glover, Yolande Strengers, and Tania Lewis. 2017. The unsustainability of academic aeromobility in Australian universities. Sustainability: Science, Practice and Policy 13, 1 (2017), 1-12.

[7] Andrew Glover, Yolande Strengers, and Tania Lewis. 2018. Sustainability and academic air travel in Australian universities. International fournal of Sustainability in Higher Education (2018).

[8] Stefan Gössling, Paul Hanna, James Higham, Scott Cohen, and Debbie Hopkins. 2019. Can we fly less? Evaluating the 'necessity'of air travel. Journal of Air Transport Management 81 (2019), 101722.

[9] Stefan Gössling and Paul Upham. 2012. Climate change and aviation: issues, challenges and solutions. Routledge.

[10] James ES Higham, Debbie Hopkins, and Caroline Orchiston. 2019. The worksociology of academic aeromobility at remote institutions. Mobilities 14, 5 (2019), 612-631.

[11] Debbie Hopkins, James Higham, Caroline Orchiston, and Tara Duncan. 2019. Practising academic mobilities: Bodies, networks and institutional rhythms. The Geographical fournal 185, 4 (2019), 472-484.

[12] Debbie Hopkins, James Higham, Sarah Tapp, and Tara Duncan. 2016. Academic mobility in the Anthropocene era: a comparative study of university policy at three New Zealand institutions. Fournal of Sustainable Tourism 24, 3 (2016), 376-397.

[13] Niels Jungbluth and Christoph Meili. 2019. Recommendations for calculation of the global warming potential of aviation including the radiative forcing index. The International fournal of Life Cycle Assessment 24, 3 (2019), 404-411.

[14] David S Lee, David W Fahey, Piers M Forster, Peter J Newton, Ron CN Wit, Ling L Lim, Bethan Owen, and Robert Sausen. 2009. Aviation and global climate change in the 21st century. Atmospheric Environment 43, 22-23 (2009), 3520-3537.

[15] Samuel Mann, Oliver Emile Glaves Bates, and Raymond Maher. 2018. Shifting the maturity needle of ICT for Sustainability. In Proceedings of the ICT for Sustainability (ICT4S) conference (ICT4S '18). Atlantis Press.

[16] Kari Marie Norgaard. 2011. Living in denial: Climate change, emotions, and everyday life. mit Press.

[17] Markus Robèrt. 2007. Mobility management and climate change policies. Ph.D. Dissertation. KTH.

[18] Markus Robèrt. 2009. A Model for Climate Target-Oriented Planning and Monitoring of Corporate Travel. International Journal of Sustainable Transportation 3, 
$1(2009), 1-17$.

[19] Johan Rockström, Owen Gaffney, Joeri Rogelj, Malte Meinshausen, Nebojsa Nakicenovic, and Hans Joachim Schellnhuber. 2017. A roadmap for rapid decarbonization. Science 355, 6331 (2017), 1269-1271.

[20] Tom Storme, Jonathan V Beaverstock, Ben Derrudder, James R Faulconbridge, and Frank Witlox. 2013. How to cope with mobility expectations in academia Individual travel strategies of tenured academics at Ghent University, Flanders. Research in Transportation Business \& Management 9 (2013), 12-20.

[21] Tom Storme, James R Faulconbridge, Jonathan V Beaverstock, Ben Derudder, and Frank Witlox. 2017. Mobility and professional networks in academia: An exploration of the obligations of presence. Mobilities 12, 3 (2017), 405-424.
[22] Yolande Strengers. 2014. Fly or die: Air Travel and the internationalisation of academic careers. Demand Centre Online Article (2014).

[23] Maria Wolrath Söderberg and Nina Wormbs. 2019. Grounded: Beyond flygskam. European Liberal Forum \& Fores.

[24] Seth Wynes and Simon D Donner. 2018. Addressing greenhouse gas emissions from business-related air travel at public institutions: a case study of the University of British Columbia. Pacific Institute for Climate Solutions.

[25] Seth Wynes, Simon D Donner, Steuart Tannason, and Noni Nabors. 2019. Academic air travel has a limited influence on professional success. Fournal of cleaner production 226 (2019), 959-967. 